\section{Murder Dalam Pembelajaran Membaca Memahami Bahasa Jerman}

\author{
Imma Tahir ${ }^{1}$, Jufri' ${ }^{2}$, Abd. Kasim Achmad ${ }^{3}$ \\ Universitas Negeri Makassar \\ Email: immatahir5@gmail.com
}

\begin{abstract}
Abstrak. Tujuan penelitian ini untuk memeroleh data dan informasi mengenai keefektifan model Cooperative learning tipe MURDER dalam pembelajaran membaca memahami bahasa Jerman siswa kelas XI MIPA SMAN 16 Makassar. Jenis penelitian ini adalah Pre-Experimental Design (one group pretest postest design). Populasi penelitian adalah siswa kelas XI MIPA SMA Negeri 16 Makassar yang terdiri atas 1 kelas yang berjumlah 36 siswa.Sampel penelitian ini dipilih menggunakan total sampling. Data dianalisis dengan uji-t.Hasil analisis data menunjukkan bahwa nilai thitung $2,40 \geq$ $t_{\text {tabel }}$ 1,997 pada taraf signifikan 0,05. Hasil penelitian ini menunjukkan bahwa model Cooperative learning tipe MURDER dalam pembelajaran membaca memahami bahasa Jerman Kelas XI MIPA SMA Negeri 16 Makassar efektif.
\end{abstract}

Kata Kunci: Keefektifan, Cooperative learning, MURDER, Membaca memahami
INTERFERENCE Journal of Language, Literature,and Linguistics

\section{E-ISSN: 2721-1835 \\ P-ISSN: 2721-1827}
Submitted
: May $3^{\text {rd }}, 2021$
Accepted
: May $22^{\text {th }}, 2021$

Abstract. The purpose of this study to obtain data and information about the effectiveness of the Murder type Cooperative Learning model in reading learning to understand German language for students of class XI MIPA SMAN 16 Makassar. The type of research is the PreExperimental Design (one group pretest postest design). The study population was the students of class XI MIPA SMA Negeri 16 Makassar which consisted of 1 class totaling 36 students. The sample of this study was selected using total sampling. Data were analyzed by t-test. The results of data analysis showed that the value of $t$ count $2.40 \geq t$ table 1.997 at a significant level of 0.05 . The results of this study indicate that the cooperative learning model of MURDER type in reading learning to understand German for Class XI MIPA SMA Negeri 16 Makassar is effective 


\section{PENDAHULUAN}

Pendidikan memegang peranan penting dalam mencerdaskan kehidupan bangsa, oleh karena itu setiap individu yang terlibat dalam pendidkan dituntut berperan serta secara maksimal guna meningkatkan mutu pendidikan tersebut. Pendidikan mencakup beberapa komponen, dua diantaranya adalah guru dan siswa. Agar proses pembelajaran berhasil, guru harus berperan secara aktif, untuk memberi motivasi kepada siswa agar aktif belajar dan memberikan pengalaman belajar kepada siswa.

Kurikulum 2013 diharapkan dapat menghasilkan lulusan yang berkarakter, kompeten dan literat untuk siap menghadapi tantangan Abad 21. Pembelajaran pada abad ini merupakan pembelajaran yang berusaha mengitegrasikan kemampuan literasi, kecakapan pengetahuan, keterampilan dan sikap, serta penguasaan terhadap teknologi.

Model kurikulum berbasis kompetensi dengan standar kompetensi lulusan yang ditetapkan untuk satu satuan pendidikan dan program pendidikan. Selain memiliki perinsip utama, kurikulum 2013 memiliki empat aspek penilaian, yaitu : (KI1) Spritual, (KI-2) Sosial, (KI-3) Pengetahuan dan (KI-4) Keterampilan.

Sejalan dengan hal itu, kompetensi dalam mempelajari bahasa asing khususnya bahasa Jerman di SMA/MA yaitu siswa diharapkan mampu menggunakan beragam fungsi sosial kebahasaan untuk berkomunikasi baik lisan maupun tulisan dalam berbagai situasi dan topik dengan bahasa Jerman yang mencakup empat kompetensi yang perlu dikuasai yaitu: keterampilan menyimak (Hörverstehen), keterampilan berbicara (Sprechfertigkeit), kemampuan membaca (Leseverstehen), keterampilan menulis (Schreiberfertigkeit). Keempat keterampilan berbahasa tersebut ditunjang oleh dua kemampuan yaitu tata bahasa (Strukturen) dan kosakata (Wortschat). Hal tersebut merupakan satu kesatuan yang memegang peranan dalam keberhasilan proses pembelajaran siswa. Untuk mendukung hal tersebut akan dibahas salah satu kompetensi yaitu kemampuan membaca (Leseverstehen).

Penguasaan membaca memahami yang baik sangat diperlukan dalam pembelajaran bahasa Jerman. Kompetensi dasar yang perlu dicapai dalam pembelajaran membaca pemahaman adalah siswa mampu memahami teks berbentuk paparan atau dialog sederhana mengenai kehidupan sehari-hari. Hal ini menjadi dasar dibutuhkannya pelajaran membaca pemahaman bahasa Jerman, sehingga siswa mampu memahami dan mengerti apa yang dibaca. Dalam pembelajaran membaca memahami teks bahasa Jerman, siswa perlu untuk memahami apa yang dibacanya.

Berdasarkan hasil observasi yang dilakukan dengan guru bahasa Jerman yang mengajar serta pengamatan peneliti pada saat melakukan kegiatan PPL, diperoleh informasi bahwa siswa kesulitan dalam semua aspek pembelajaran yaitu membaca, menyimak, berbicara dan menulis. Guru menyatakan bahwa hal tersebut terjadi karena adanya hambatan-hambatan yang dihadapi siswa dalam belajar, diantaranya kurangnya pembendaharaan kosakata yang dimiliki siswa, serta kurangnya minat dan motivasi siswa dalam belajar sehingga siswa kurang aktif dalam proses pembelajaran. Penelitian terdahulu terkait pembelajaran membaca 
memahami bahasa Jerman telah dilakukan oleh (Tahir, R. A., Rijal, S., \& Fatimah, S., 2020; Sanusi, Y. H., Mannahali, M., \& Anwar, M., 2020; Mawaresna, A., \& Anwar, M., 2020) bahwa rata-rata kemampuan membaca memahami siswa masih dalam kategori cukup.

Berkaitan dengan kondisi di atas, diperlukan serangkaian upaya oleh guru untuk meningkatkan kualitas pembelajaran membaca sehingga tercapainya tujuan pembelajaran membaca. Salah satu upaya tersebut adalah dengan memperkenalkan prosedur pembelajaran membaca yang mampu membentuk perilaku membaca sekaligus mampu mengembangkan kemampuan membaca. Kegiatan pembelajaran yang dikembangkan bersifat kolaboratif dan kooperatif. Sesuai dengan pilar kecakapan abad 21 yang mencakup $4 \mathrm{C}$ yang dikemukakan oleh Anis Baswedan dalam pidatonya mengenai penigkatan mutu pendidikan (Republika, 2016): kecakapan berpikir kritis (critical thinking and problem solving), berkomunikasi (communication skill), kreativitas dan inovasi (creativity and innovation), kolaborasi (collaboration).

Salah satu upaya yang dapat dilakukan dengan menerapkan model pembelajaran membaca yang dapat menumbuhkan minat belajar siswa dengan mudah bisa dipaham dan diterima oleh siswa. Model pembelajaran MURDER (mood, understand, recall, detect, elaborate dan review) yang dihasilkan oleh psikologi kognitif. Mood yang berarti suasana hati, understand yang berarti paham, recall yang berarti ingat, detect yang berarti menemukan kesalahan, elaborate yang berarti pengalaman dan review yang berarti ulang.

Diharapkan dengan model pembelajaran tersebut seorang siswa akan mengalami keberhasilan dalam belajar terutama dalam hal atau kategori ranah kognitif. Ranah psikologis siswa yang terpenting adalah ranah kognitif. Ranah kejiwaan yang berkedudukan di otak ini, dalam perspektif psikologis kognitif adalah sumber sekaligus pengendali ranah-ranah kejiwaan lainnya, yakni ranah afektif (rasa) dan ranah psikomotorik (karsa).

Berdasarkan latar belakang tersebut, disusun rumusan masalah tentang hasil Pretest pada kemampuan membaca memahami siswa kelas XI MIPA hasil Postest pada kemampuan membaca memahami siswa kelas XI MIPA dengan menggunakan model cooperative learning tipe MURDER dan mengenai efektivitas model cooperative learning tipe MURDER terhadap peningkatan kemampuan memahami siswa kelas XI MIPA.

Penelitian ini dilakukan dengan tujuan untuk mengetahui hasil Pretest pada kemampuan membaca memahami siswa kelas XI MIPA untuk mengetahui hasil Postest pada kemampuan membaca memahami dengan menggunakan model cooperative learning tipe MURDER dan untuk memeroleh data tentang keefektifan model cooperative learning tipe MURDER dalam kemampuan membaca memahami siswa kelas XI MIPA

Istilah model diartikan sebagai kerangka konseptual yang digunakan sebagai pedoman dalam melakukan suatu kegiatan. Trianto (2010:51) berpendapat “Model pembelajaran adalah suatu perencanaan atau suatu pola yang digunakan sebagai pedoaman dalam merencanakan pembelajaran di kelas atau pembelajaran dalam tutorial". Selanjutnya, menurut Mulyasa (2014;142) berpendapat “Model 
pembelajaran adalah bentuk pembelajaran yang tergambar dari awal sampai akhir yang disajikan secara khas oleh guru”.

Abidin (2014:116) menyatakan "Model pembelajaran dapat diartikan sebagai suatu konsep yang membantu menjelaskan proses pembelajaran, baik menjelaskan pola pikir maupun pola tindakan pembelajaran tersebut". Selain itu, Joice dan Weil dalam Isjoni (2016:50) mengemukakan bahwa model pembelajaran adalah suatu pola atau rencana yang sudah direncanakan sedemikian rupa dan digunakan untuk menyusun kurikulum, mengatur materi pelajaran dan memberi petunjuk kepada pengajar di kelasnya.

Dari beberapa pendapat dapat disimpulkan bahwa model pembelajaran adalah bentuk pembelajaran yang tergambar dari awal sampai akhir yang disajikan secara khas oleh guru dan digunakan untuk menyusun kurikulum, mengatur materi pelajaran dan memberi petunjuk kepada pengajar di kelasnya.

\section{COOPERATIVE LEARNING TIPE MURDER}

Salah satu model cooperative learning yang akan digunakan nantinya dalam meningkatkan kemampuan membaca siswa, ialah dengan menggunakan cooperative learning tipe MURDER.

Model pembalajaran MURDER merupakan bagian dari metode cooperative learning yang dihasilkan oleh Hythecker, Dansereau dan Rocklin. Hythecker dalam Santyasa (2008:15) mengemukakan bahwa MURDER merupakan salah satu model pembelajaran yang dihasilkan dari perspektif psikologi kognitif, dimana siswa nantinya akan berfokus bagaimana ia memproleh, menyimpan dan memproses apa yang dipelajarinya.

Mood berarti mengatur suasana hati yang tepat dengan cara relaksasi dan berfokus pada tugas belajar, Santyasa (2008:15). Proses Pembelajaran adalah proses yang dapat mengembangkan seluruh potensi siswa. Seluruh potensi itu hanya mungkin dapat berkembang manakala siswa terbebas dari rasa takut dan menegangkan. Hal ini sejalan dengan pendapat dari Uno (2006: 82) secara umum ranah suasana hati meliputi optimisme yaitu kemampuan untuk mempertahankan sikap positif yang realisitis dalam menghadapi masa-masa sulit dan kebahagiaan yaitu kemampuan untuk menyukai diri sendiri dan orang lain serta bergairah dalam melakukan setiap kegiatan.

Understand atau Pemahaman adalah tahap kedua dari model pembelajaran MURDER. Tahap ini siswa didorong untuk membaca dan memahami materi yang disajikan dan menandai hal-hal yang belum dimengerti. Hal ini senada dengan penjelasan dari Santyasa (2008:15) mengatakan bahwa Understand artinya membaca bagian materi tertentu dari naskah tanpa menghafalkan.

Recall berarti siswa berusaha mengingat kembali apa yang sudah mereka baca Santyasa (2008:15) Recall, artinya salah satu anggota kelompok memberikan sajian lisan dengan mengulang materi yang dibaca.

Proses pengulangan akan membuat informasi yang telah diperoleh bertahan lebih dalam untuk disimpan dalam ingatan siswa. Menurut Djamarah (2010:109) menerima suatu pesan, informasi atau komunikasi meliputi kemampuan mengekspresikan dengan kata-kata lain, mengembangkan ringkasan yang lebih 
teliti, menuliskan kembali dalam bentuk verbal atau memberi contoh khusus untuk mengilustrasikan ide yang abstrak.

Detect berarti menemukan kesalahan. Santyasa (2008:15) menjelaskan bahwa penemuan kesalahan dilakukan oleh anggota lain terhadap munculnya kesalahan atau kealpaan catatan.

Elaborate Menurut Wittock dalam Slavin (2005: 38) jika informasi ingin dipertahankan dalam memori dan berhubungan dengan informasi yang sudah ada, orang yang belajar harus terlibat dalam semacam pengaturan kembali kognitif atau elaborasi dari materi.

Suatu proses pembelajaran akan berlangsung dengan efektif apabila informasi yang dipelajari dapat diingat dengan baik dan terhindar dari lupa. Review Menurut Sarlito dalam Ramlah (2015:13) menjelaskan bahwa Mengingat adalah perbuatan menyimpan hal-hal yang sudah pernah diketahui untuk pada suatu saat lain dikeluarkan dan digunakan kembali.

\section{MEMBACA MEMAHAMI}

Menurut Tarigan (2015:7) Membaca adalah suatu proses yang dilakukan serta dipergunakan oleh pembaca untuk memperoleh pesan, yang hendak disampaikan oleh penulis melalui media kata-kata/bahasa tulis. Dalam hal ini, membaca berarti suatu usaha untuk menelusuri makna yang ada dalam tulisan.

Membaca merupakan aktivitas fisik dan mental yang bertujuan untuk memahami teks dan dapatkan arti teksnya. Saat membaca, mata kita akan tertuju pada kalimat dan otak kita akan menyerap isi teks dan akan menyimpannya penyimpanan (Widiawati, T., Nuraida, I., \& Saputri, S. W., 2020; Jumarni, S., Saud, S., \& Sukmawaty, S., 2021; Mutmainna, M., \& Burhanuddin, B., 2018).

Dalman (2014:5) mengemukakan bahwa membaca merupakan suatu kegiatan atau proses kognitif yang berupaya untuk menentukan berbagai informasi yang terdapat dalam tulisan. Hal ini berarti membaca adalah suatu proses berpikir untuk memahami isi teks yang dibaca. Pada dasarnya kegiatan membaca bertujuan untuk mencari dan memeroleh pesan atau memahami makna yang terkandung dalam sebuah bacaan. Tarigan (2015:9) berpendapat bahwa membaca bertujuan untuk mencari serta memperoleh informasi, mencakup isi, memahami makna bacaan. Pengertian membaca memahami dijelaskan oleh Somadoyo (2011:10) bahwa "membaca memahami merupakan suatu proses pemerolehan makna yang secara aktif melibatkan pengetahuan dan pengalaman yang telah dimiliki oleh pembaca serta dihubungkan dengan isi bacaan".

\section{METODE PENELITIAN}

Metode penelitian yang digunakan dalam penelitian ini adalah PreEksperimental Design. Dikatakan Pre-Eksperimental Designs dikarenakan masih terdapat variabel luar yang ikut berpengaruh terhadap terbentuknya hasil eksperimen, hal ini dapat terjadi, karena tidak adanya variabel kontrol, dan sampel tidak dipilih secara acak.

Pada penelitian ini peneliti menggunakan desain penelitian one group pretest postest design. one group pretest-posttest design adalah kegiatan penelitian yang memberikan tes akhir (posttest) dengan demikian hasil perlakuan dapat 
diketahui lebih akurat karena dapat membandingkan dengan keadaan sebelum diberikan perlakuan.

Secara sederhana, desain penelitian ini dapat digambarkan sebagai berikut:

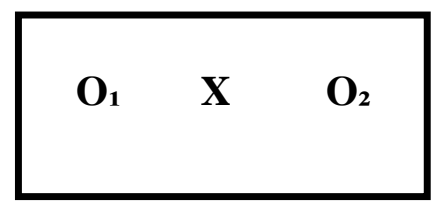

$\mathrm{O}_{1} \quad$ : Nilai pretest (sebelum diberikan diklat)

$\mathrm{O}_{2} \quad$ : Nilai Posttest (setelah diberikan diklat)

$\mathrm{X} \quad$ :Treatment (perlakuan)

Populasi dalam peneltian ini adalah siswa kelas XI MIPA yang belajar bahasa Jerman. Adapun jumlah kelas yang belajar bahasa Jerman hanya berjumlah 1 kelas, dikarenakan kelas yang awalnya berjumlah 2 dilebur menjadi 1 kelas. Sampel dalam penelitian ini adalah siswa kelas XI IPA 6 yang berjumlah 36 orang. Teknik pengumpulan sampel dalam penelitian ini adalah total sampling. Alasan menggunakan total sampling karena jumlah kelas XI yang belajar bahasa Jerman hanya terdapat satu kelas.

Teknik pengumpulan data yang digunakan dalam penelitian ini dilakukan melalui tes kemampuan membaca memahami bahasa Jerman. Tes tersebut terdiri atas dua bagian, yaitu tes awal (pre-test) yang diberikan sebelum diberikan Treatment, setelah pemberian tes awal (pre-test) dilanjutkan dengan memberikan Model Cooperative learning tipe MURDER Sebanyak 4 kali pertemuan secara daring dan terakhir pemberian tes akhir (post-test). Kedua bagian tes ini memiliki prosedur penilaian untuk setiap komponen sebagai berikut:

1. Pilihan ganda berjumlah 10 butir soal. Jawaban benar memperoleh skor 1 dan jawaban salah memperoleh skor 0 . Jadi skor maksimal adalah 10.

2. Richtig-Falsch (R-F) berjumlah 6 butir soal. Jawaban benar memperoleh skor 1 dan jawaban salah memperoleh skor o. Jadi skor maksimal adalah 6.

\section{TEKNIK ANALISIS DATA}

Teknik analisis data dalam penelitian ini menggunakan analisis statistika deskriptif dan inferensial untuk menguji hipotesis penelitian dengan menggunakan uji-t. Sebelum melakukan pengujian tersebut terlebih dahulu dilakukan uji normalitas dengan menggunakan tabel Z-score dan chi kuadrat.

\section{HASIL DAN PEMBAHASAN}

\section{Analisis Data Deskriptif Data Pre-Test Dan Post-Test}

Berdasakan analisis data yang diperoleh pada kelas XI MIPA yaitu, mean (rata-rata) pre-test siswa kelas tersebut adalah 60,64 termasuk kategori Cukup dengan nilai tertinggi adalah 88 dan nilai terendah adalah 13. Sedangkan rata-rata (mean) post-test siswa kelas tersebut adalah 84,50 dengan nilai tertinggi adalah 94 dan nilai terendah adalah 62.

Gambaran lebih jelasnya tersusun dari skor terendah sampai dengan skor tertinggi beserta frekuensinya dapat dilihat pada tabel di bawah ini: 
Tabel 4.1 Distribusi Frekuensi dan Persentase Nilai Pretest

\begin{tabular}{clll}
\hline Kelas & Interval Kelas & Frekuensi & Persentase(\%) \\
\hline 1 & $12,5-25,00$ & 2 & 5,56 \\
\hline 2 & $25,01-37,51$ & 6 & 16,67 \\
\hline 3 & $37,52-50,02$ & 6 & 16,67 \\
\hline 4 & $50,03-62,53$ & 6 & 16,67 \\
\hline 5 & $62,54-75,04$ & 4 & 11,11 \\
\hline 6 & $74,05-87,55$ & 12 & 33,33 \\
\hline Jumlah & & 36 & 100 \\
\hline
\end{tabular}

Berdasarkan data di atas dapat disimpulkan bahwa terdapat 33,33\% siswa yang memeroleh nilai tertinggi pada kelas interval dengan rentangan 74,05 - 87,55, sedangkan terdapat $5,56 \%$ siswa yang memeroleh nilai terendah pada kelas interval dengan rentangan 12,5 - 25,00

Tabel 4.2 Distribusi Frekuensi dan Persentase Nilai Post-test

\begin{tabular}{cccc}
\hline Kelas & Interval Kelas & $\mathrm{f}_{\mathrm{i}}$ & Persentase $(\%)$ \\
\hline 1 & $68,75-72,91$ & 2 & $5,56 \%$ \\
\hline 2 & $72,92-77,08$ & 2 & $5,56 \%$ \\
\hline 3 & $77,09-81,25$ & 11 & $30,56 \%$ \\
\hline 4 & $81,26-85,42$ & 0 & $0 \%$ \\
\hline 5 & $85,43-89,59$ & 13 & $36,11 \%$ \\
\hline 6 & $89,60-93,76$ & 8 & $22,22 \%$ \\
\hline Jumlah & & 36 & 100 \\
\hline
\end{tabular}

Berdasarkan data di atas dapat disimpulkan bahwa terdapat 22,22\% siswa yang memeroleh nilai tertinggi pada kelas interval dengan rentangan 89,60 - 93,76 sedangkan terdapat 2 kelas interval yang memiliki tingkat persentase $5,56 \%$ pemerolehan nilai terendah yaitu antara 68,75 -72,91 dan 72,92 - 77,08 dan tidak ada siswa $0 \%$ yang memperoleh nilai pada kelas interval dengan rentangan 81,26 85,59 .

\section{PEMBAHASAN}

Berdasarkan hasil uji t diketahui rata-rata pre-test 60,64 setelah dilakukan post-test 84,50 sehingga peningkatanya sebesar 23,86 . Selanjutnya berdasarkan uji t diperoleh nilai thitung 2,40. Nilai tabel dengan $\mathrm{dk} 70$ pada taraf signifikan 0,05 adalah 1,997. Oleh karena itu $t_{\text {hitung }}>t_{\text {tabel }}(2,40>1,997)$ sehingga dapat dinyatakan terdapat peningkatan secara signifikan pada skor hasil belajar siswa setelah dibeikan model cooperative learning tipe MURDER.

Model cooperative learning tipe MURDER merupakan model pembelajaran yang berfokus terhadap cara memeroleh, menyimpan dan memproses apa yang 
dipelajari siswa. Proses pembelajaran menggunakan model cooperative learning tipe MURDER pada awalnya ingin dilaksanakan pada pembelajaran tatap muka, namun karena adanya aturan pemerintah mengenai pembelajaran yang dilaksanakan di rumah maka pembelajaran terlaksana dengan menggunakan media daring. Adapun media yang digunakan yaitu diantaranya Video Conference Zoom, WhatsApp dan Google Formulir.

Pada pertemuan pertama siswa diberikan Pre-test secara daring melalui laman https://forms.gle/Lby8NwmnPgSugyBS7 kemudian pada pertemuan berikutnya pemberian treatment dengan menggunakan Model cooperative learning tipe MURDER. Guru mengecek kehadiran dan kesiapan siswa untuk mengikuti pembelajaran daring melalui Video Conference Zoom. Selanjutnya, guru menciptakan suasana hati (Mood) yang nyaman dan menyenangkan bagi siswa untuk belajar dengan cara memberikan games atau pemutaran video motivasi. Namun, karena waktu pembelajaran daring yang singkat, maka dari itu penciptaan Mood dilakukan dengan cara guru memberikan kata-kata ataupun kalimat motivasi kepada siswa agar tetap semangat dalam mengikuti pembelajaran daring. Kemudian siswa dibagi menjadi beberapa kelompok, dimana masing-masing kelompok beranggotakan 4 dan dalam setiap kelompok membentuk 2 pasangan. Pembentukan kelompok dilakukan secara daring dan masing-masing kelompok membuat grup di aplikasi WhatsApp.

Setelah pembentukan kelompok selesai, selanjutnya guru membagikan teks bacaan melalui WhatsApp. Masing-masing pasangan dalam setiap kelompok membentuk pemahaman (Understand) dengan cara salah satu anggota dalam pasangan mencari informasi dalam teks dan anggota lainnya menulis serta mengoreksi kesalahan.

Dikarenakan prosesnya pembelajarn terlaksana melalui daring, maka dari itu diskusi setiap anggota kelompok terlaksana secara daring dengan menggunakan grup WhatsApp. Selanjutnya guru meminta siswa untuk mengecek dan mengulang kembali untuk membaca teks bacaan (Recall) dengan cara menyatukan informasi dari kedua pasangan dan menyatukan ide-ide utama (Elaborate). Setelah sesi diskusi antara anggota kelompok selesai, selanjutnya guru melakukan peninjauan hasil kinerja kelompok (Review). Masing-masing kelompok menyampaikan secara bergantian kesimpulan ide-ide utama yang diperoleh dari teks bacaan melalui Video Conference Zoom. Setelah 4 kali pertemuan siswa diberi post-test melalui Google Formulir dengan laman https://forms.gle/k6wejGDegtqiNPT Pembelajaran dengan menggunakan media online tentunya memberikan tantangan tersendiri bagi guru. Dimana siswa tidak terlalu merespon guru, tidak adanya semangat untuk mengikuti pembelajaran, siswa tidak hadir dan keluhan mengenai keterbatasan kuota internet yang dimiliki siswa. Penerapan model cooperative learning tipe MURDER dalam pembelajaran daring juga memiliki hambatan tersendiri dimana diskusi kelompok yang biasanya dilakukan secara langsung harus dilakukan melalui daring dan hal tersebut bsa dikatakan kurang efektif karena guru mengalami kesulitan untuk mengontrol keaktifan siswa. Meskipun terdapat banyak hambatan yang dilalui yang tentunya terjadi setiap minggunya maka dari itu untuk mengatasinya guru 
mengevaluasi kekurangan-kekurangan yang ada di setiap pertemuan agar pertemuan berikutnya hal tersebut dapat diminimalisir.

Berdasarkan hasil analisis data yang menyatakan bahwa adanya peningkatan hasil belajar siswa sebelum dan sesudah menggunakan model cooperative learning tipe MURDER menunjukkan bahwa MURDER dapat menjadikan siswa lebih aktif dalam proses pembelajaran sehingga pemahaman siswa mengenai bahan ajar khususnya dalam pembelajaran membaca memahami lebih baik dibandingkan model pembelajaran dengan metode ceramah yang membuat siswa mudah bosan.

\section{KESIMPULAN}

Berdasarkan rumusan masalah, hasil penelitian dan pembahasan dalam penelitian ini dapat disimpulkan bahwa hsil Pre-test pada pembelajaran membaca memahami siswa kelas XI MIPA sebelum menggunakan model cooperative learning tipe MURDER menunjukkan bahwa nilai yang diperoleh siswa terbilang rendah dimana siswa memeroleh nilai antara 12,5- 87,5, dimana nilai rata-rata keseluruhan siswa sebanyak 60,59. Setelah diberikan perlakuan (treatment) sedangkan hasil Post-test pada pembelajaran membaca memahami siswa kelas XI MIPA dengan menggunakan model cooperative learning tipe MURDER menunjukkan adanya peningkatan terhadap nilai siswa. Hal ini dibuktikan dengan meningkatnya nilai ratarata siswa menjadi 85,24 . dengan demikian, model Cooperative learning tipe MURDER dalam pembelajaran membaca memahami teks bahasa Jerman siswa kelas XI MIPA dinyatakan efektif. Hal tersebut dibuktikan dari hasil analisis uji-t pada nilai siswa setelah dilakukan uji-t dengan hasil analisis data yaitu $t_{\text {hitung }}=\mathbf{2 , 4 0}>t_{\text {tabel }}=$ 1,997 pada taraf signifikansi 0,05.

\section{DAFTAR PUSTAKA}

Abidin, Y. (2016) . Desain Sistem Pembelajaran dalam Konteks Kurikulum 2013. Bandung: PT Refika Aditama.

Dalman. (2014). Keterampilan membaca. Jakarta: Raja Grafindo Persada

Djamarah, S. B. (2010). Guru Anak Didik Dalam Interaksi Edukatif:Suatu Pendekatan Teoritis Psikologi. Jakarta: PT Rineka Cipta.

Https://republika.co.id/berita/pendidikan/education/16/02/06/024uep284-strategi4cuntuk-tingkatan-mutu-pendidikan diaksses tanggal 11 Maret 2021 pukul 13.30 WITA

Isjoni. (2010). Cooperative Learning. Bandung: Alfabeta.

Jumarni, S., Saud, S., \& Sukmawaty, S. (2021). Kemampuan Membaca Bahasa Mandarin Siswa Sekolah Dasar. Interference: Journal of Language, Literature, and Linguistics, 2(1), 42-48.

Mawaresna, A., \& Anwar, M. (2020). HUBUNGAN ANTARA PENGUASAAN KOSAKATA (WORTSCHATZ) DENGAN KEMAMPUAN MEMBACA MEMAHAMI (LESEVERSTEHEN) TEKS BAHASA JERMAN SISWA KELAS XI. Interference: Journal of Language, Literature, and Linguistics, 1(2), 153-158.

Mulyasa. (2014). Guru dalam implementasi kurikulum 2013,. Bandung : PT. Remaja Rosdakarya Offset. 
Mutmainna, M., \& Burhanuddin, B. (2018). PENINGKATAN KEMAMPUAN MEMBACA BAHASA JERMAN MELALUI PENDEKATAN SCIENTIFIC. Eralingua: Jurnal Pendidikan Bahasa Asing dan Sastra, 2(2).

Ramlah, R. (2015). Pengaruh Kemampuan Mengingat Terhadap Hasil Belajar IPA Peserta Didik Kelas VI MI AN-Nashar Makassar. Skripsi. Makassar : UIN.

Santyasa, I W. (2008). Pembelajaran Berbasis Masalah dan Pembelajaran Koopertaif.Nusa Penida.

Sanusi, Y. H., Mannahali, M., \& Anwar, M. (2020). KEEFEKTIFAN PENGGUNAAN MODEL COOPERATIVE LEARNING TIPE STUDENT TEAMS ACHIEVEMENT DIVISIONS (STAD) DALAM KEMAMPUAN MEMBACA TEKS BAHASA JERMAN SISWA KELAS X MIPA SMA NEGERI 1 BARRU. Interference: Journal of Language, Literature, and Linguistics, 1(1).

Slavin, R. E. (2005). Cooperative Learning: Teori, Riset, Praktik. Bandung: Nusa Media.

Somadoyo, Samsu. 2011. Strategi dan Teknik Pembelajaran Membaca. Yogyakarta: Graha Ilmu.

Tahir, R. A., Rijal, S., \& Fatimah, S. (2020). KEEFEKTIFAN PENGGUNAAN TEKNIK THINK PAIR SHARE (TPS) DALAM KETERAMPILAN MEMBACA MEMAHAMI BAHASA JERMAN SISWA KELAS X SMA NEGERI 1 KAB. BARRU. Interference: Journal of Language, Literature, and Linguistics, 1(1).

Tarigan, H. G. (2015). Membaca sebagai suatu Keterampilan Berbahasa. Bandung: Angkasa.

Trianto. (2010). Model Pembelajaran Terpadu. Jakarta: PT Bumi Aksara.

Uno, H. B. (2006). Orientasi Baru dalamPsikolosi Pembelajaran. Jakarta: PT Bumi Aksara.

Widiawati, T., Nuraida, I., \& Saputri, S. W. (2020). IMPROVING THE STUDENT'S READING SKILL TROUGH SQ3R TECHNIQUE IN MTS AL-KHAIRIYAH. Interference: Journal of Language, Literature, and Linguistics, 1(1). 